rashes to ampicillin was associated with its administration to patients with glandular fever (18 out of 19 patients $=95 \%$ ) (Pullen, Wright, and Murdoch, 1967).

Because of the uncertainty about the true incidence of cutaneous reactions to ampicillin, it was considered of interest to carry out a complete survey of the published clinical literature (Lynn, 1969). It was found that ampicillin treatment had been described in a total of 13,638 patients up to 1 March 1969, and it was reported that 384 subjects had experienced skin reactions of one kind or another-an incidence of $2.8 \%$. The reported skin reactions may be classified as shown in Table III.

TABLE III.-Incidence of Various Types of Skin Reaction Reported During Ampicillin Therapy (Lynn, 1969)

\begin{tabular}{|c|c|c|c|c|c|}
\hline \multicolumn{3}{|l|}{ Type of Rash } & $\begin{array}{c}\begin{array}{c}\text { No. } \\
\text { reported }\end{array} \\
60 \\
23 \\
10\end{array}$ & $\begin{array}{c}\begin{array}{c}\% \text { of total } \\
\text { patients } \\
\text { treated }\end{array} \\
0.44 \\
0 \cdot 17 \\
0.07 \\
\end{array}$ & $\begin{array}{c}\begin{array}{c}\% \text { of total } \\
\text { skin } \\
\text { reactions }\end{array} \\
\begin{array}{c}15 \cdot 6 \\
6 \cdot 0 \\
2 \cdot 6\end{array}\end{array}$ \\
\hline 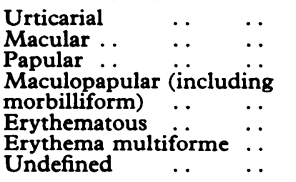 & $\begin{array}{l}\cdots \\
\cdots \\
\cdots \\
\cdots \\
\cdots\end{array}$ & $\begin{array}{l}\cdots \\
\cdots \\
\cdots \\
\cdots \\
\cdots\end{array}$ & $\begin{array}{r}60 \\
23 \\
10 \\
114 \\
7 \\
1 \\
169\end{array}$ & $\begin{array}{l}0.44 \\
0.17 \\
0.07 \\
0.83 \\
0.05 \\
0.01 \\
1.24\end{array}$ & $\begin{array}{r}15 \cdot 6 \\
6.0 \\
2.6 \\
29 \cdot 7 \\
1.8 \\
0.3 \\
44.0\end{array}$ \\
\hline & & & 384 & $2 \cdot 81$ & \\
\hline
\end{tabular}

An incidence of $3.1 \%$ with type B would appear to be consistent with that determined from the above survey of the international literature. Consideration of the type of infection associated with the higher incidence of rashes might suggest that the use of ampicillin for the treatment of conditions that in themselves are often associated with a rash (typhoid and paratyphoid fever, glandular fever, etc.) tends to increase the overall incidence of skin eruptions. In view of the bactericidal action of ampicillin, a rash might also be associated with rapid lysis of intestinal organisms giving rise to skin-sensitizing "agents." The results of this study, however, suggest that one of the factors involved is the presence of penicilloyl protein impurity. As the material is also responsible for the induction of antibodies in experimental animals and, in particular, of skin-sensitizing antibodies in a primate species, it is tempting to speculate that the rash may have an underlying allergic or immunological mechanism. It may be significant that the most dramatic effect seen in this trial was the reduction in maculopapular rashes in patients treated with purified ampicillin. This was the type of rash described in baboons, and further studies in this species may shed light on the aetiology of this condition and its relation to the presence or absence of skin-sensitizing antibodies. Further clinical studies have been instituted to obtain comprehensive data on the possible mode of action of the impurity, dosage dependence, signs of generalized systemic hypersensitivity, and relation of the type of rash to conventional penicillin allergy and future penicillin treatment of the patient.

Meanwhile, the recognition of impurities and the introduction of control procedures to eliminate them results in ampicillin of increased and controlled purity, and it is expected that this increased purity will lead to a reduction in the numbers of adverse reactions to ampicillin, whether these are of allergic or of immunological aetiology. Beecham Research Laboratories have instituted the controlled procedures outlined above for 6-APA, and all Penbritin (ampicillin) currently made by them should have a lower rash potential.

REFERENCES

Batchelor, F. R., Dewdney,, Janet, M., Feinberg, J. G., and Weston, R. D. (1967). Lancet, 1, 1175.

Cuellar, G., and Puente, R. (1967). Current Therapeutic Research, 9,

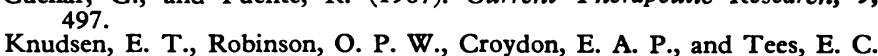
(1967). Lancet, 1, 1184.

Lynn, B. (1969). Beecham Research Laboratories Medical Records.

Personal communication.
Munden, J. (1965) British Patent Application No. 48995/65.

Pullen, H., Wright, N., and Murdoch, J. McC. (1967). Lancet, 2, 117.6.

Shapiro, S., Slone, D., Siskind, V., Lewis, G. P., and Jick, H. (1969) Lancet, 2, 969.

Sleet, R. A., Sangster, G., and Murdoch, J. McC. (1964). British Medical fournal, 1, 148.

Stevenson, J., and Mandal, B. (1966). British Medical fournal, 1, 1359.

Stewart, G. T. (1967). Lancet, 1, 1177.

Thiel, J. A., Mitchell, Shirley, and Parker, C. W. (1964). fournal of Allergy, 35, 399.

Walker, W. (1965). Scottish Medical fournal, 10, 466.

Willcox, R. R. (1963). British fournal of Venereal Diseases, 39, 164.

\title{
Controlled Trial of Propranolol in Hypertension
}

\author{
F. J. ZACHARIAS, ${ }^{*}$ M.D., F.R.C.P.; K. J. COWEN, $†$ м.B., в.CH.
}

$S^{u}$ mmary: A trial of oral propranolol as a hypotensive agent was designed to provide adequate treatment periods. Twenty-eight patients with essential hypertension, with a mean blood pressure of $190 / 111 \mathrm{~mm}$. $\mathrm{Hg}$, were controlled on $120-320 \mathrm{mg}$. of propranolol daily. Their mean treated blood pressure was 153/91. They then entered, on a randomized and double-blind basis, a cross-over trial of two 16-week periods, blood pressure being measured fortnightly. Propranolol caused a statistically significant fall in blood pressure when compared with placebo. When propranolol was withdrawn blood pressures rapidly rose to hypertensive levels, though not to untreated levels. No postural hypotension was found, but a small change in blood pressure levels on exercise was noted.

\footnotetext{
* Consultant Physician.

† General Practitioner and Clinical Assistant, Hypertension Unit, Clatterbridge General Hospital, Wirral, Cheshire.
}

The first report that a beta-adrenergic antagonist, when given orally to hypertensive subjects, would reduce blood pressure came in 1964 and followed work with pronethalol (Prichard, 1964). When pronethalol was replaced by propranolol there followed several reports of its oral use in hypertension. These reports may be divided into two groups. In the first group propranolol was given in an open and uncontrolled mannerthat is, not double-blind. The results seemed to indicate modest benefit with relatively small doses (Waal, 1966; Richards, 1966; Gebhardt et al., 1967) and appreciable hypotensive action with slightly larger doses (Frohlich et al., 1968; Tewari and Grant, 1968). Prichard and Gillam (1966, 1969), with greater flexibility of dosage, concluded that propranolol is an effective hypotensive drug, comparable in potency to guanethidine, bethanidine, or methyldopa.

In the second group propranolol was given in clinical trials having either a cross-over design (Paterson and Dollery, 1966) 
or a double-blind design (Richardson et al., 1967; Humphreys and Delvin, 1968) and in this group no significant hypotensive action was shown. In one trial (Paterson and Dollery, 1966) propranolol in daily doses of 80 and $240 \mathrm{mg}$. was no more effective in reducing blood pressure than $50 \mathrm{mg}$. of hydrochlorothiazide; in another (Richardson et al., 1967) propranolol in daily doses of $120 \mathrm{mg}$. was no more effective than a placebo, and in the same trial no difference was shown between the hypotensive effect of $100 \mathrm{mg}$. of chlorthalidone daily and chlorthalidone (100 mg./day) combined with propranolol (120 mg./day); in another trial (Humphreys and Delvin, 1968) propranolol in doses of 240 and $360 \mathrm{mg}$. daily was no more effective than a placebo.

There is some discrepancy between the results of the two groups. It is also noted that in the most comprehensive of the open trials-that of Prichard and Gillam (1969)-propranclol was used for longer periods and in higher total dosage than in the controlled trials. In view of their evidence that the onset of hypotensive action may be delayed for six to eight weeks, it may be that the failure of the controlled trials to confirm the results of the open ones lies in a failure to use long enough periods of treatment.

More important, in our view, is the dosage used. Prichard and Gillam (1969) emphasized the great variability in optimum dosage. In a long-term study of more than 300 patients observed for up to five years our experience has been similar, more than $30 \%$ of the patients requiring $600 \mathrm{mg}$. or more daily and more than $15 \%$ requiring $1,000 \mathrm{mg}$. or more daily. It would not be surprising, therefore, if the much smaller doses used in the previous controlled trials proved inadequate. The present trial was designed to eliminate these factors by observing for a long time (two 16-week periods), by making the only therapeutic variable the presence or absence of propranolol, and, in particular, by studying patients in whom the optimum dose was already known, and who had been stabilized for at least 11 months before the start of the trial.

\section{Method}

Out of over 300 patients with essential hypertension whose blood pressures had been stabilized on propranolol 32 were chosen for this trial. These patients satisfied two criteria: firstly, they had all responded to propranolol, and, secondly, their dose did not exceed $320 \mathrm{mg}$. daily. This upper dose limit was chosen arbitrarily as we were not sure of the effect of suddenly changing from placebo to doses of propranolol higher than this.

All but two received bendrofluazide and potassium supplements. Once blood pressure was stabilized the patients continued treatment for an average of 21.9 months (range 11 to 50 months) before entry to the trial. The trial was so designed that on entry patients either continued their current dose of propranolol or began on the same number of identical placebo tablets, both for 16 weeks. At the end of this period a crossover occurred and the patients continued for another 16 weeks. Entry to a particular sequence (propranolol-placebo or placebo-propranolol) was arranged on a randomized and double-blind basis.

Patients were seen at fortnightly intervals, when blood pressure was measured at rest in the supine, sitting, and standing positions, and also sitting after a standard one-minute exercise test. Pulse rate was measured by another observer at the same time as the blood pressure measurements were taken. At each visit patients were questioned regarding side-effects and other symptoms.

Four patients were withdrawn from the trial. One had kept some of her previous propranolol tablets and subsequently mixed these up with her trial tablets, which on breaking the code proved to be placebo. One patient developed fresh retinal haemorrhages after 14 weeks in the trial. It was found that she also had been taking placebo tablets, and propranolol was restarted, whereupon her blood pressure fell from $230 / 140$ to $140 / 85 \mathrm{~mm}$. $\mathrm{Hg}$ in four weeks. Two more were excluded because of irregular attendance due to intercurrent illness.

\section{Results}

General.-The age range of the 28 patients (17 men and 11 women) was 37 to 69 (mean 51.5) years and the periods of treatment on propranolol before the trial were from 15 to 55 (mean 35.2) months. Blood pressure measurements had been controlled for periods of 11 to 50 months, with a mean of 21.9 months before entry to the trial. Untreated blood pressure levels ranged from $165 / 98$ to $245 / 153$, with a mean of $190 / 111$. The daily dose of propranolol, given before meals in four divided doses, was $320 \mathrm{mg}$. in 13 patients, $240 \mathrm{mg}$. in five, 160 $\mathrm{mg}$. in nine, and $120 \mathrm{mg}$. in one.

Effect of Propranolol on Blood Pressure.-The mean blood pressure at rest and on exercise for each sequence group is shown in Tables I and II. Statistically there is a highly signi-

TABLE I.-Mean Resting Blood Pressures in mm. Hg Before Treatment When Controlled on Treatment, and During Trial

\begin{tabular}{cc|c|c|c|c|c|c}
\hline \multicolumn{1}{c|}{ Group } & $\begin{array}{c}\text { Pre- } \\
\text { treatment }\end{array}$ & $\begin{array}{c}\text { Pretrial } \\
\text { Control }\end{array}$ & Drug & Placebo & Difference & $\begin{array}{c}\text { S.E. of } \\
\text { Difference }\end{array}$ \\
\hline $\begin{array}{l}\text { Drug to placebo } \\
\text { sequence }\end{array}$ & $\ldots$ & $\frac{190}{111}$ & $\frac{154}{92}$ & $\frac{145}{86}$ & $\frac{164}{100}$ & $19^{*}$ & 1.56 \\
\hline $\begin{array}{l}\text { Placebo to drug } \\
\text { sequence }\end{array}$ &. & $\frac{191}{111}$ & $\frac{151}{89}$ & $\frac{137}{83}$ & $\frac{164}{102}$ & $24^{*}$ & 1.39 \\
\hline Mean &.. & $\frac{190}{111}$ & $\frac{153}{91}$ & $\frac{142}{85}$ & $\frac{164}{101}$ & $22^{*}$ & 1.01 \\
\hline
\end{tabular}

* Significant at $0 \cdot 1 \%$.

TABle II.-Mean Exercise Blood Pressures in mm. Hg When Controlled on Treatment and During Trial

\begin{tabular}{|c|c|c|c|c|c|}
\hline Group & $\begin{array}{c}\text { Pre-trial } \\
\text { Control }\end{array}$ & Drug & Placebo & Difference & $\begin{array}{l}\text { S.E. of } \\
\text { Difference }\end{array}$ \\
\hline \multirow{2}{*}{ Drug to placebo sequence } & 154 & 149 & 188 & $39^{*}$ & $2 \cdot 52$ \\
\hline & $\overline{87}$ & $\overline{80}$ & $\overline{99}$ & $19 *$ & $1 \cdot 24$ \\
\hline \multirow{2}{*}{ Placebo to drug sequence } & 153 & 139 & 183 & 44* & $3 \cdot 81$ \\
\hline & $\overline{88}$ & 77 & 98 & $21^{*}$ & 1.49 \\
\hline \multirow{2}{*}{$\begin{array}{llll} & & \ldots & \end{array}$} & 154 & 145 & 186 & $41 *$ & $3 \cdot 2$ \\
\hline & 87 & 79 & $\overline{99}$ & $20^{*}$ & $1 \cdot 4$ \\
\hline
\end{tabular}

* Significant at $0 \cdot 1 \%$

ficant difference both at rest and on exercise . between mean pressures in the treated compared with the untreated groups in both sequences $(P<0.001)$. The mean fall in blood pressure was $22 / 16 \mathrm{~mm} . \mathrm{Hg}$ at rest and $41 / 20 \mathrm{~mm}$. $\mathrm{Hg}$ after exercise.

Effect of Changing from Placebo to Propranolol and Vice Versa.-It can clearly be seen from Fig. 1 that there is a pronounced change in blood pressure at the cross-over point. The probability of such a change occurring by chance, should the drug be ineffective, is less than $0.1 \%(\mathrm{P}<0.001)$. It is also clear that pressures do not rise to untreated levels even with placebo. The magnitude of the change in blood pressure was greater on changing from placebo to propranolol than vice versa, but this difference was not seen in the exercise pressures.

Effect of Posture on Blood Pressure in Propranolol-treated Group.-There were no significant differences between blood 


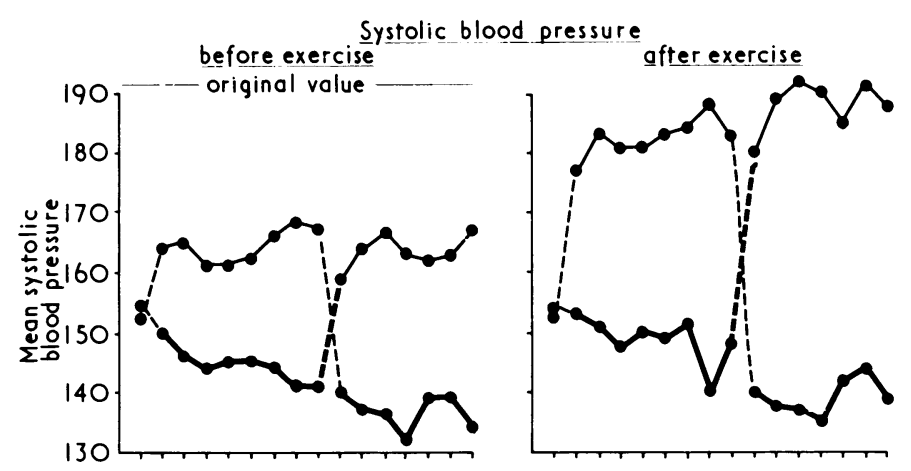

before exercise
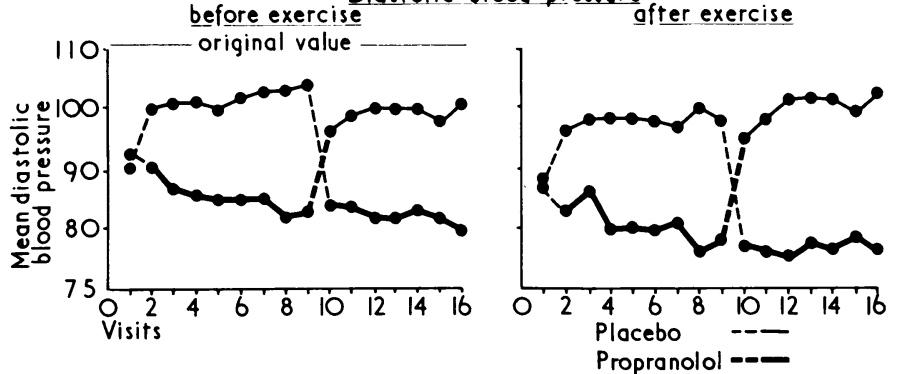

FIG. 1.- Mean systolic and diastolic blood pressures at rest and on exercise during the trial.

pressure measurements in the standing, sitting, and lying positions $(\mathrm{P}>0.05)$ (Table III).

TABle III.-Mean Resting Blood Pressures in mm. Hg in Supine, Sitting, and Standing Positions When Controlled on Treatment and During Trial

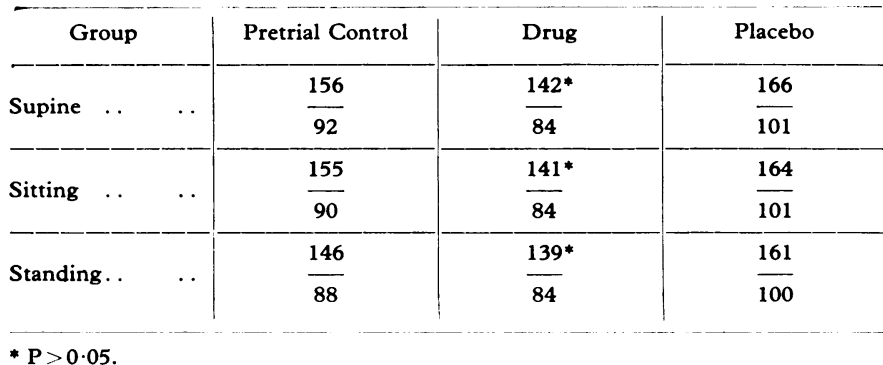

Effect of Exercise on Blood Pressure in Propranolol-treated Group.-A comparison of resting and exercise blood pressures for patients on propranolol showed a small rise in systolic and a small fall in diastolic pressures following exercise (Table IV).

TABLE IV.-Mean Blood Pressures in mm. Hg at Rest and on Exercise While on Propranolol

\begin{tabular}{c|c|c|c|c}
\hline Group & Resting & $\begin{array}{c}\text { After } \\
\text { Exercise }\end{array}$ & $\begin{array}{c}\text { Mean } \\
\text { Difference }\end{array}$ & $\begin{array}{c}\text { S.E. of } \\
\text { Difference }\end{array}$ \\
\hline Drug to placebo sequence & $\frac{145}{86}$ & $\frac{149}{80}$ & $+4 \cdot 4^{*}$ & 1.4 \\
\hline Placebo to drug sequence & $\frac{137}{83}$ & $\frac{139}{77}$ & $+2 \cdot 4^{*}$ & 0.9 \\
\hline
\end{tabular}

* Significant at $1 \%$.

Statistical analysis showed this diastolic fall to be significant at the $1 \%$ level in both sequence groups, and the systolic rise to be significant, also at the $1 \%$ level, but only in the propranololplacebo sequence group.
Effect of Propranolol on Pulse Rate and its Relation to Blood Pressure Changes.-There was a significant change in pulse rate at the cross-over point (Fig. 2) both at rest and on exercise $(\mathrm{P}<0.001)$.

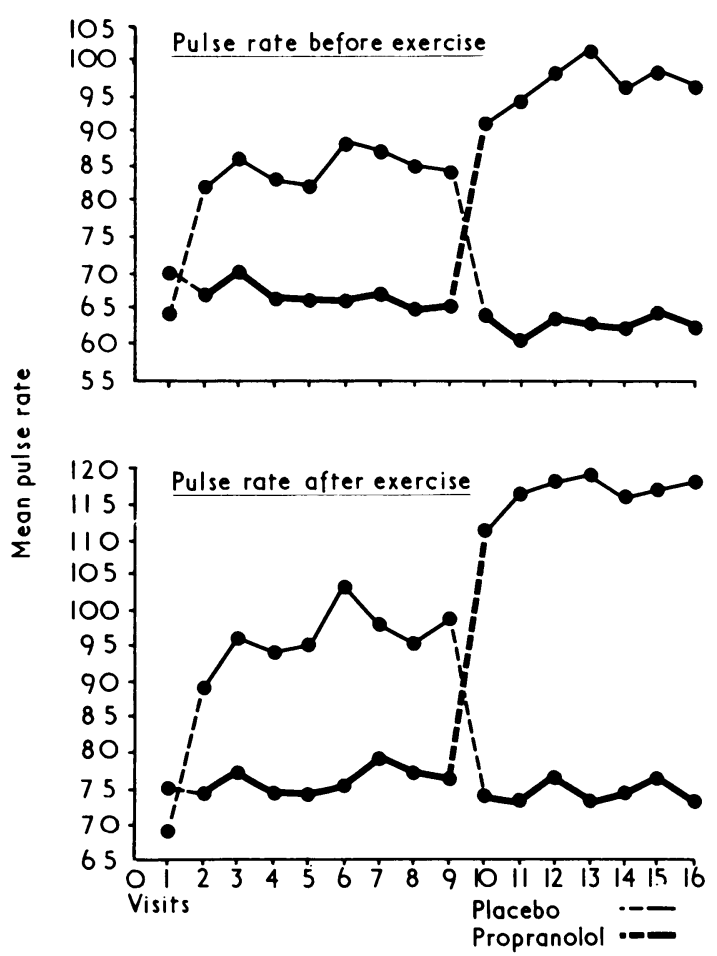

FIG. 2.-Mean pulse rates at rest and on exercise during the trial

\section{Discussion}

As it is intended to report separately our clinical experience in a five-year trial of propranolol in more than 300 hypertensive patients (Zacharias and Cowen, in preparation), discussion here is limited to the specific implications of this trial.

The mean untreated blood pressure of the patients studied was $190 / 111 \mathrm{~mm}$. Hg. Once their pressures had been brought under control with propranolol before entry to the trial the mean level was $153 / 91 \mathrm{~mm}$. $\mathrm{Hg}$, which is both statistically significant and a clinically satisfactory reduction. That this difference in blood pressure was due to propranolol is shown by reference to the cross-over point of the trial (Fig. 1). The mean blood pressure on placebo was $164 / 101 \mathrm{~mm}$. $\mathrm{Hg}$, whereas that for propranolol during the trial was $142 / 85 \mathrm{~mm}$. $\mathrm{Hg}$, this reduction being highly significant.

Two factors appear to be involved in the changes in blood pressure seen in this trial. There is a rapidly acting one, the effect of which is seen at the cross-over point, and is clearly due to propranolol, possibly acting via a reduction in cardiac output as was shown by Frohlich et al. (1968).

That a second factor is involved is suggested by the fact that even when patients had been off propranolol for 16 weeks in the trial their mean blood pressures did not rise to untreated levels (though they may have done so had propranolol been withheld longer). This phenomenon is unlikely to be due to persistence of the drug in the body, as its halflife in man is only about two hours. It is possible that there has been a change in the natural history of the disorder during treatment. This could be a spontaneous change, or one induced by propranolol. If it were induced by propranolol a possible mechanism would be the resetting of baroreceptor responses as postulated by Prichard and Gillam $(1966,1969)$. Such a re- 
setting need not necessarily produce a permanent change in the natural history of the disorder, however, but may simply be an effect that requires more than 16 weeks to disappear. The most likely explanation, however, of the failure of blood pressure to return to pretreatment levels is that the diuretic therapy, which was kept constant throughout the trial, continued to exert a mild hypotensive effect.

It is also seen that in the group of patients who on entry to the trial continued taking propranolol there was a significant fall both in systolic $(P<0.05)$ and diastolic $(P<0.01)$ blood pressures, in spite of an unaltered dose for a mean period of 21.9 months. Over the first period of the trial the fall in diastolic pressure on propranolol was about $2 \mathrm{~mm}$. $\mathrm{Hg} /$ month. This effect is probably due to the increased attention inevitably received by patients during any clinical trial.

The results in Fig. 2 show the reduction of heart rate commonly associated with propranolol. It was not possible, however, to use the pulse rate as a clinical guide to the fall in blood pressure that was seen in these patients.

There was no clinical evidence of postural or exercise hypotension in propranolol-treated patients, and blood pressure measurements confirmed the lack of postural hypotension. There was, however, a small rise in systolic pressure of about $3.6 \mathrm{~mm}$. $\mathrm{Hg}$, and a small fall in diastolic pressure of about 5.7 $\mathrm{mm}$. $\mathrm{Hg}$, occurring on exercise in patients on propranolol. Although these were clinically small changes, statistical analysis showed the diastolic falls to be significant at the $1 \%$ level in both sequence groups, and the systolic rise to be significant (also at $1 \%$ ) but only in the propranolol-placebo sequence group.

We wish to thank Imperial Chemical Industries Ltd. (Pharmaceuticals Division) for the supply of propranolol and placebo tablets. We are indebted to the medical and statistical staff of the Clinical Research Department, Alderley Park, for their assistance in the preparation of this paper, and to the nursing staff of the hypertension unit and the pharmaceutical department of Clatterbridge Hospital for their co-operation throughout the trial.

\section{REFERENCES}

Frohlich, E. D., Tazari, R. C., Dustan, H. P., and Page, I. H. (1968) Circulation, 37, 417

Gebhardt, W., et al. (1967). Wiener Klinische Wochenschrift, 79, 337. Humphreys, G. S., and Delvin, D. G. (1968). British Medical fournal, 2, 601.

Paterson, J. W., and Dollery, C. T. (1966). Lancet, 2, 1148.

Prichard, B. N. C. (1964). British Medical fournal, 1, 1227.

Prichard, B. N. C., and Gillam, P. M. S. (1966). American fournal of Cardiology, 18, 387.

Prichard, B. N. C., and Gillam, P. M. S. (1969). British Medical Fournal, 1, 7 .

Richardson, D. W., Freund, J., Gear, A. S., Mauck, H. P., jun., and Preston, L. W.'(1967). Circulation, 37, 534.

Richards, F. A. (1966). American fournal of Cardiology, 18, 384.

Tewari, S. N., and Grant, R. H. E. (1968). Postgraduate Medical fournal, 44, 509.

Waal, H. J. (1966). Clinical Pharmacology and Therapeutics, 7, 588.

\section{Hypotension Caused by L-Dopa}

\section{B. CALNE, ${ }^{*}$ D.M., M.R.C.P. ; JENNIFER BRENNAN, $\dagger$ B.SC., M.SC. ; A. S. D. SPIERS, ${ }^{*}$ PH.D., M.R.A.C.P.} G. M. STERN, $\ddagger$ M.D., M.R.C.P.

\begin{abstract}
Summary: In 20 patients with idiopathic Parkin$S$ sonism maximum tolerated doses of $L$-dopa were found to induce a mean reduction in blood pressure (erect systolic) of $19.3 \mathrm{~mm} . \mathrm{Hg}$, without any significant change in pulse rate. This hypotension may be due to dopamine, acting on adrenergic nerve endings or on the central nervous system itself.
\end{abstract}

\section{Introduction}

It has been reported that both hypertension and hypotension may occur in patients undergoing treatment with L-dopa for Parkinsonism (Cotzias et al., 1968; 1969; Yahr et al., 1968; Calne et al., 1969; Duvoisin et al., 1969; Godwin-Austen et al., 1969). Details of the extent of blood pressure changes have not been previously reported.

\section{Methods}

We have studied the blood pressure and pulse rate in 20 idiopathic Parkinsonian patients who had been receiving maximum tolerated dosage of oral L-dopa for a minimum of six weeks. We repeated the observations six weeks after

* Research Fellow, University College Hospital, London W.C.1. Present address: Hammersmith Hospital, Ducane Road, London W.12. † Student, Department of Medical Statistics and Epidemiology, London School of Hygiene and Tropical Medicine, London W.C.1. ¥ Consultant Neurologist, University College Hospital, London W.C.1. switching to inert tablets. Patients were unaware of the change to placebo unless decoding occurred as a result of the substantial clinical deterioration which of ten too's place when Ldopa was stopped. The blood pressure was measured with a standard sphygmomanometer and the pulse by palpation of the radial artery.

The patient lay down on a couch, and the blood pressure and pulse rate were immediately recorded. Observations were repeated after the patient had been supine for three minutes and again one minute after standing erect. The initial measurements on lying down were discarded (they were carried out only as a conditioning manoeuvre to accustom patients to the recording situation). Statistical analyses were performed on the observations made three minutes after lying down and one minute after standing. These are referred to as the "supine" values and "erect" values. The mean dose of L-dopa was 3 g. per day (range 1-8 g.).

\section{Results}

The results are shown in the Table of mean values. Paired sample $t$ tests were used to establish the significance levels of the differences. It is evident that L-dopa lowered both the systolic and the diastolic blood pressure in the erect and supine positions. In addition, it augmented the postural drop in both systolic and diastolic pressures. No significant change in pulse rate was induced by L-dopa. In $75 \%$ of the patients the 